\title{
Hacia lo monstruoso
}

Huellas de Edgar Allan Poe en Leopoldo María Panero

\section{Joaquín Ruano}

\section{(2) OpenEdition}

Journals

Edición electrónica

URL: http://journals.openedition.org/agedor/705

DOI: 10.4000/agedor.705

ISSN: 2104-3353

Editor

Laboratoire LISAA

\section{Referencia electrónica}

Joaquín Ruano, "Hacia lo monstruoso », L'Âge d'or [En línea], 7 | 2014, Publicado el 01 marzo 2014, consultado el 01 mayo 2019. URL : http://journals.openedition.org/agedor/705 ; DOI : 10.4000/

agedor.705

L'Âge d'or. Images dans le monde ibérique et ibéricoaméricain 


\title{
Hacia lo monstruoso: huellas de Edgar Allan Poe en Leopoldo María Panero
}

\author{
A Leopoldo, in memoriam: ya te has reunido con la nada, ya te has convertido en poesía.
}

Résumé : L'œuvre de l'écrivain espagnol Leopoldo María Panero se constitue comme un entretien infatigable avec une tradition littéraire qui conçoit l'écriture comme transgression des paramètres établis (esthétiques, philosophiques, politiques, vitaux). L'un de ces interlocuteurs n'est autre qu'Edgar Allan Poe, avec qui Panero établira une alliance contre la poésie utilitariste. Dans ce but, comme on verra dans la comparaison entre les œuvres des deux écrivains, la poésie doit elle-même chercher les aspects les plus obscurs de l'âme humaine.

Mots-clés: Leopoldo María Panero - Edgar Allan Poe - Intertextualité - Littérature d’horreur Transgression.

Resumen: La obra del escritor español Leopoldo María Panero se constituye como un diálogo incansable con una tradición literaria que concibe la escritura como transgresión de los parámetros establecidos (estéticos, filosóficos, políticos, vitales). Uno de esos interlocutores es Edgar Allan Poe, con el cual Panero establecerá una alianza contra la poesía utilitarista. Para ello, como veremos en la comparación de ambas obras, la poesía debe buscar los aspectos más oscuros del alma humana.

Palabras clave: Leopoldo María Panero - Edgar Allan Poe - Intertextualidad - Literatura de Terror - Transgresión.

\section{Citar, subvertir}

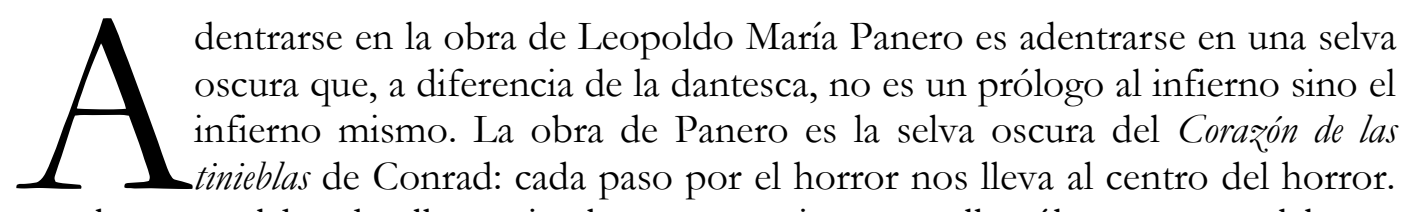

En esta selva textual hay huellas, animales que transitan por ella sólo para que el lector pueda construir un sentido a lo que no lo tiene o, mejor, a lo que no tiene más sentido que el propio devenir por la oscuridad del enorme sistema de citas de la escritura paneriana. Como dice Alessandro Mistrorigo, su obra es en sí un ecosistema literario:

La realidad a la que alude Panero, en efecto, es y ha sido siempre literaria. Su poesía se ha establecido siempre en el diálogo con todo discurso literario - o cultural - anterior. Lo cual explica que, por una parte, "la sobreabundancia de citas (no siempre correctas) y de 
referencias a otros textos que atraviesa tanto la escritura-Panero como la persona-Panero », y, por otra, el desvalimiento de la inspiración y del valor de la originalidad de raíz romántica; así que " lo único que hay que hacer es conectar datos que ya existen, que siempre han existido». ${ }^{1}$

(Eco)sistema de citas, diálogo en la oscuridad que trasciende sin embargo el mero ejercicio estilístico, que no se queda en una estéril muestra de erudición, sino que tienen un propósito muy claro: " [...] l'intertextualité panérienne met sur un même plan d'égalité la tradition académique, le monde des contes, des films, des BD, des chansons [...] défaisant les hiérarchies établies et détruisant les classifications conventionnelles ", dice Claudie Terrasson ${ }^{2}$. La subversión de las estructuras se convierte por tanto en marca, en patente de corso paneriana en todos los estratos que un texto puede tener: pragmático, estilístico, semántico, etc. Es decir, que la labor de escritura y reescritura, de diálogo y apropiación de otros textos, la constitución de la densa y oscura biblioteca que es la obra de Leopoldo María Panero, pretende - como en una orgía sadiana - consumar las posibilidades del lenguaje, es decir, agotarlas:

[la escritura de Leopoldo María Panero] Constituye, por tanto, un diseño poético de la autoinfracción, que tan sólo se justifica en el constante y continuo desenmascaramiento de su espíritu y de su propia letra. [...] Sin embargo, dicho diseño poético se propone consumar las infinitas posibilidades del lenguaje porque se presenta prioritariamente como cíclica (re)escritura de todo acto de lectura: « toda la literatura no es sino una inmensa prueba de imprenta y nosotros, los escritores últimos o póstumos somos tan sólo correctores de prueba » afirma Panero. En última instancia la labor del escritor no es sino colaborar con la infinita elaboración de esa suerte de 'palimpsesto final' que es la literatura y sobre el cual Leopoldo María Panero funda su concepción de la tragedia misma de toda escritura. ${ }^{3}$.

Vemos, por tanto, traslucir en la interpretación que leemos arriba, que la (re)escritura de Panero pone en juego algo más que el mero concepto kristeviano de intertextualidad, que la selva, el palimpsesto perpetuo que forma la obra de Leopoldo María Panero es la disolución del sujeto, el remate de la literatura, la muerte del autor y, por consiguiente, de la noción jerarquizada de la literatura:

Dentro de esta perspectiva, la presencia de los recursos intertextuales e interdiscursivos de que se compone la poesía de Panero se acompaña siempre de una rabiosa y "repetida negación de lo poético (es decir de lo artístico) en cuanto tal"; tal vez, por "la necesidad de resguardarse tras el parapeto de la autoridad ajena al emitir un discurso que se sabe transgresor" y no creíble o, tal vez, porque la dispersión, la fragmentación y la destrucción de todo discurso que resulta de aquella conciencia fragmentaria es el único horizonte de experiencia que se le presenta al sujeto que escribe y que no consigue dar un sentido unitario

\footnotetext{
1 MISTRORIGO, Alessandro, "No hay nada, nada más que la boca que dice": Horizonte poético de Leopoldo María Panero ", in BOU Enric y PITTARELLO Elide (eds.) (En)claves de la Transición. Una visión de los novísimos: Prosa, poesía, ensayo, Vervuert / Iberoamericana, Madrid / Frankfurt, 2009, p. 333.

2 TERRASSON, Claudie, "L'œuvre poétique de Leopoldo María Panero : une écriture hors-normes », in Lieux et figures de la barbarie, CECILLE - EA 4074, Université de Lille 3, 2006-2008, p. 9. http:/ / evenements.univ-lille3.fr/colloque-barbarie2008/seminaires/Claudie-Terrasson.pdf

3 RODRÍGUEZ DE ARCE, Ignacio, "Poética de la intertextualidad en Leopoldo María Panero », in Ogigia. Revista electrónica de estudios hispánicos, nº 6, 2009, p. 30.

http:/ / dialnet.unirioja.es/servlet/ ejemplar?codigo $=230198$
} 
a su escritura. De acuerdo con el sujeto posmoderno, el yo poético de Panero se vuelve esquizofrénico, entre los discursos propios y ajenos. ${ }^{4}$

O, como el propio Panero decía en 1977, de lo que se trata es de abrir, ante la constatación de una literatura acabada, las posibilidades infinitas de una literatura ensimismada:

Esa sería la literatura $[\ldots]$ « de la posibilidad agotada »[...] la literatura que explore las posibilidades inexistentes que quedan para una literatura nueva. La literatura que [...] tome su referente no en la realidad sino en la literatura misma - es decir, en su Ser, su pasado -, considerándola como un todo ya dado, a descubrir precisamente como tal. La literatura póstuma: el « détournement ». [...] esa literatura ya no dará cuenta de ninguna realidad ni de ningún estatuto epistemológico exterior a ella que no sea el dado en el juego - ya sabido y por lo tanto mejorable - de la literatura, multiplicada sólo por sí misma. ${ }^{5}$

¿Estamos, por tanto, ante un comienzo o ante un acabamiento? ¿Nos encontramos al abordar la salvaje política de reescritura paneriana - ante el apocalipsis de la literatura o ante su resurrección, no ya como Nueva Jerusalén, sino como Nueva Babilonia? ${ }^{6}$ ? Son preguntas que no admiten, ante la complejidad del concepto literario en una obra como la que tratamos, una respuesta tajante, maniquea. Sí que podemos afirmar, en cualquier caso, que, como dice Zulima Martínez « Leopoldo María se re-escribe constantemente [...] Poetizar es una maldición para el hombre porque lo va destruyendo poco a poco. Necesita destruirlo para existir [...] $»^{7}$. Como si del eterno juego de Eros y Tánatos se tratara, lo cierto es que, en el universo poético y estético de Leopoldo María Panero se crea un espacio donde la muerte se hace vivible o, aún, donde la muerte es el único espacio vivible; lo cual, hablando en textos intraliterarios, significa que la muerte es lo único que se puede decir:

En el régimen figural, retórico, el significante es una unidad móvil, caracterizada por el principio del desplazamiento y de la metamorfosis; algo 'todavía por interpretar'. Panero, sin embargo, concibe la muerte como único significante. Parece decirnos: "la lengua es un sistema de la muerte ». En el régimen figural, en los artificios retóricos y poéticos, el significante-muerte puede desplazarse y metamorfosearse, (re)interpretarse, (re)elaborarse y (re)escribirse, pero solo especularmente, reflexivamente; de ahí que el lenguaje sea un «sistema de citas » dominado por el significante-muerte y el autor un « corrector de pruebas». El poema (sobre/en) el poema de Panero no sería sino una especial declinación del tema del ensimismarse de la muerte. ${ }^{8}$

\footnotetext{
${ }^{4}$ MISTRORIGO, Alessandro, " "No hay nada, nada más que la boca que dice": Horizonte poético de Leopoldo María Panero », op. cit., p. 335.

5 PANERO, Leopoldo María, Visión de la literatura de Terror Anglo-Americana, Madrid, Felmar, 1977, p. 23.

${ }^{6}$ No creo que sea baladí el uso de esta terminología (anti)mística. Como mostré - o como intenté mostrar en mi texto "'La sinagoga de Satanás". Presencias heréticas en la poesía de Leopoldo María Panero » (in Castilla. Estudios de Literatura, 2, 2011 p. 123-149) la reflexión poética paneriana toma muchísimo del pensamiento herético y se constituye, por tanto, en herejía, en desvirtualización del "dogma" literario - con lo que ello conlleva en la filosofía paneriana de desvirtualización de todos los dogmas: morales, políticos, sociales, etc - .

${ }^{7}$ MARTÍNEZ RODRÍGUEZ, Zulima, « Construcción del universo de Leopoldo María Panero a partir de la negación y de la interpretación de la realidad » en Actas del congreso "La transición de la dictadura franquista a la democracia", Barcelona, Centre d'Estudis sobre les Èpoques Franquista i Democràtica - UAB, 2005, p. 488.

${ }^{8}$ RODRÍGUEZ DE ARCE, Ignacio, "Poética de la intertextualidad en Leopoldo María Panero ", op. cit., p. 37.
} 
Pero, si debemos señalar un principio por el que la escritura de Leopoldo María Panero se rija, si su escritura acepta someterse, aún sin traicionarlo al instante, a un paradigma, ese es el precepto nietzscheano de que la vida y el arte son inseparables ${ }^{9}$; ahora bien: el hecho de que para Panero la vida y el arte son inseparables no significa, en absoluto, que la escritura esté subordinada a lo biográfico sino que, muy por el contrario, que ambas - literatura y vida - vuelan juntas en plano de igualdad, haciendo de su conjunción un frenesí inseparable, a la vez creador y destructor, apolíneo y dionisíaco. Esto significa, además, que los procedimientos, como hemos leído arriba, retóricos no se circunscriben, bajo ningún concepto al simple florilegio o motivo figural, sino que - y este es el compromiso revolucionario paneriano - cubren toda la existencia. Así, la muerte no se circunscribe a una maniobra epistemológica, sino que, al revés, es tan sólo una faceta más del proceso por el cual, « Lo siniestro va filtrándose en la realidad cotidiana. Las cosas - en el límite entre lo real y lo fantástico - aparecen como realidades subjetivas que sólo se significan en lo real, cosas-símbolo que manifiestan la distancia con lo simbolizado y que adquieren vida propia $»^{10}$. Otra faceta muy importante de este proceso es que, como bien apunta Claudie Terrasson, se produce una estetización de la muerte ${ }^{11}$. Ahora bien, si hemos dicho que la escritura de Panero no se concibe sino como un entramado de intertextos, como una selva oscura donde la autoría se disuelve en una obra que está plagada de voces, huellas, terroríficas, que se imbrican destruyendo la(s) jerarquía(s) textual(es), entonces también aquí debemos encontrar una filiación a lo siniestro, a esta estetización de la muerte. Y no podemos estar más de acuerdo con Julia Barella que cuando dice: "Su tratamiento de lo mágico, de lo siniestro o fantástico viene de la mano de Poe, de Lautréamont, de Hoffman [sic], sin duda sus maestros y guías en la penetración del terror en la literatura $»^{12}$. En las siguientes líneas, por tanto, seguiremos los trazos, las marcas de esa filiación terrorífica, siniestra y mortal que se encuentra en la obra de Leopoldo María Panero, centrándonos para ello, por ser una de las más patentes, en la del autor americano Edgar Allan Poe ${ }^{13}$.

\section{Donner un sens plus impur aux mots de la tribu.}

Si Baudelaire, comparando a la bohème con una caravana de gitanos, describía a los poetas modernos como una «tribu prophétique aux prunelles ardentes $»^{14}$, años más tarde Stéphane Mallarmé otorgaba a Poe el mérito de haber dado « un sens plus pur aux mots de

\footnotetext{
9 Véase al respecto mi artículo «De la crueldad activa: lecturas de Nietzsche en la obra de Leopoldo María Panero », in Aisthesis. Revista Chilena de Investigaciones Estéticas, n 54, 2013, p. 103-121.

${ }^{10}$ BARELLA, Julia, "La poesía de Leopoldo María Panero: entre Narciso y Edipo », in Estudios Humanísticos $\mathrm{n}^{\circ}$ 6, 1984, p. 124.

11 «Ainsi, Canto a los anarquistas, publié en 1970 présente déjà certains traits thématiques et esthétiques caractéristiques : l'esthétisation de la mort, la célébration de la beauté des cadavres associée à l'affirmation de la sensualité dans la cruauté », TERRASSON, Claudie, "L'œuvre poétique de Leopoldo María Panero : une écriture hors-normes », op. cit., p. 1.

${ }^{12}$ BARELLA, Julia, «La poesía de Leopoldo María Panero: entre Narciso y Edipo », op. cit., p. 127.

13 Quedan, por tanto, pendientes para la comprensión de la obra paneriana, un estudio detallado de las otras fuentes que nombra Barella: E.T.A. Hoffmann y Lautréamont (si bien sobre éste último ya estoy preparando un texto). Pero, más allá, creo que sería muy interesante estudiar en la narrativa de Panero la gran impronta que tiene la obra de otro autor no nombrado en la cita anterior: H.P. Lovecraft.

14 BAUDELAIRE, Charles, "Bohémiens en voyage ", in Euvres Complètes, vol. 1, París, Gallimard, Bibliothèque de la Pléiade, 1975, p. 18.
} 
la tribu» ${ }^{15}$. Ciertamente, la impronta de la obra del norteamericano en el simbolismo francés - y, por una cuestión genealógica, en la obra de Leopoldo María Panero - es innegable y enorme. En las próximas siguientes páginas, por tanto, veremos en qué consiste esa impronta, cómo da Poe un sentido más puro - o, desde el punto de vista paneriano, más impuro - a las palabras de la tribu. En los textos que Baudelaire escribe sobre Poe es obvio que el primero encuentra en la obra del segundo un apoyo indiscutible a sus propias creencias estéticas y a su convicción del comienzo de una nueva literatura, ya no expuesta al utilitarismo burgués sino, muy por el contrario, una escritura donde las formas y los mensajes se hacen ambiguos, una literatura de decadencia:

Des comparaisons grotesques s'agitent alors dans mon cerveau ; il me semble que deux femmes me sont présentées : l'une, matrone rustique, répugnante de santé et de vertu, [...] l'autre, une de ces beautés qui dominent et oppriment le souvenir, unissant à son charme profond et originel toute l'éloquence de la toilette, maitresse de sa démarche, consciente et reine d'elle-même, - une voix parlant comme un instrument bien accordé, et des regards chargés de pensée et n'en laissant couler que ce qu'ils veulent. Mon choix ne saurait être douteux, et cependant il y a des sphinx pédagogiques qui me reprocheraient de manquer à l'honneur classique $[. .$.$] Le mot littérature de décadence [. .$.$] suppose quelque chose de fatal et$ de providentiel, comme un décret inéluctable; et il est tout à fait injuste de nous reprocher d'accomplir la loi mystérieuse. ${ }^{16}$

Decadencia, por tanto de la poesía saludable, representada como la grotesca matrona, la Marianne de la República deformada por Redon. La poesía moderna se sacude, debe sacudirse, así, el yugo del utilitarismo, del didactismo. Más claro incluso había sido el propio Poe quien, en «El principio poético », tilda de herética a la poesía al servicio del sistema, la poesía utilitaria, didáctica:

While the epic mania, while the idea that to merit in poetry prolixity is indispensable, has for some years past been gradually dying out of the public mind, by mere dint of its own absurdity, we find it succeeded by a heresy too palpably false to be long tolerated, but one which, in the brief period it has already endured, may be said to have accomplished more in the corruption of our Poetical Literature than all its other enemies combined. I allude to the heresy of The Didactic. ${ }^{17}$

El poeta moderno no puede, por el contrario, sino reaccionar con horror a la implantación de un sistema donde las ciencias humanas, la gran creación del positivismo, suplantan al hombre. Como dice Baudelaire, Poe encuentra en el hombre una fuerza misteriosa que la filosofía moderna no quiere tener en cuenta; y sin embargo, a falta de esa fuerza sin nombre o de esa inclusión, muchísimas acciones humanas quedarían sin explicación posible. Pero, además, según Baudelaire, «Ces actions n’ont d'attrait que parce que elles sont mauvaises, dangereuses; elles possèdent l'attirance du gouffre ${ }^{18}$. Poe, sin

\footnotetext{
15 MALLARMÉ, Stéphane, "Le tombeau d'Edgar Poe », in Euvres Complètes, París, Gallimard, Bibliothèque de la Pléiade, 1945, p.189.

16 BAUDELAIRE, Charles, "Notes nouvelles sur Poe », in CEuvres Complètes, vol. 2, París, Gallimard, Bibliothèque de la Pléiade, 1976, p. 319-320.

17 POE, Edgar Allan, «The Poetic Principle», in The Complete Works of Edgar Allan Poe (vol. XIV: Essays Miscellanies), New York, AMC Press, 1965, p.271.

${ }^{18}$ BAUDELAIRE, Charles, « Notes nouvelles sur Poe », in CEuvres Complètes, op. cit., p. 322-323.
} 
duda menos audaz en sus afirmaciones, prefiere buscar la fuga a ese entramado teórico del positivismo. En su obra encontramos claramente el pensamiento de que, ante la imposición de las ciencias positivas, contemporáneas al autor, el poeta responde con la búsqueda del espíritu del hombre; y esto a través de lo más inherente e intemporal al ser humano, el estímulo que da constancia de la existencia de la dimensión espiritual y no sólo empírica, la belleza: «An immortal instinct deep within the spirit of man is thus plainly a sense of the Beautiful. This it is which administers to his delight in the manifold forms, and sounds, and odors and sentiments amid which he exists ${ }^{19}$. Llegamos así a uno de los puntos en los que el pensamiento de Poe puede parecer contradictorio, puesto que en el mismo movimiento que rechaza el positivismo rechaza también la inspiración. Ahora bien, no hay tal contradicción sino más bien una doble contraposición: al positivismo, a la ciencia deshumanizadora, se contrapone la búsqueda de lo bello y la vindicación, sin condiciones, de la imaginación; pero de una imaginación que no quiere en absoluto dejar paso a la improvisación, o a una categoría tan vaga como la inspiración:

L'Imagination n'est pas la fantaisie; elle n'est pas non plus la sensibilité, bien qu'il soit difficile de concevoir un homme imaginatif que ne serait pas sensible. L'Imagination est une faculté quasi divine qui perçoit tout d'abord, en dehors des méthodes philosophiques, les rapports secrets et intimes des choses, les correspondances et les analogies. Les honneurs et les fonctions qu'il [Poe] confère à cette faculté lui donnent une valeur telle [...] qu'un savant sans imagination n'apparait plus que comme un faux savant, ou tout au moins comme un savant incomplet. ${ }^{20}$

Por el contrario, para Poe, la imaginación no es lo mismo que la fantasía. La preparación del relato cobra entonces una importancia mucho mayor que la fantasía. La imaginación requiere planos, esquemas, cálculos, artificios. Es el artista quién, lejos de amoldar su pensamiento a las reglas del relato, debe planearlo, concebirlo como un sistema, como un engranaje, perfecto, como un autómata hoffmanniano:

Poe discards the Romantic organic metaphors for poetry which envisages artistic creation as a process of spontaneous growth, and redirects critical attention onto technique, to art as a clever illusion which the artist controls like a mathematical or mechanical problem. Poe's imagination was constantly drawn towards elaborate technical systems and deft scientific tricks that promise to solve the mysteries of existence. Mechanical inventions - and theories that work like mechanical inventions - are the components of the fantasy world of his tales: home-made balloons that will ascend as high as the moon; techniques of mesmerism that will take us to the other side of death; ratiocinative and intuitive intelligences, like Monsieur Dupin's, that will unravel any mystery. In his criticism Poe frequently resorts to phrenological explanations of human imaginative and intellectual powers, interrupting a discussion of Coleridge's writing, for example, with comments about the shape of his forehead. ${ }^{21}$

Haciéndose eco de lo anterior, Leopoldo María Panero ha dicho: « No creo en la inspiración, yo cultivo el espanto como una ciencia »" El análisis que de su poema “El

\footnotetext{
${ }^{19}$ POE, Edgar Allan, «The Poetic Principle », in The Complete Works of Edgar Allan Poe, op. cit., p. 237.

${ }^{20}$ BAUDELAIRE, Charles, "Notes nouvelles sur Poe ", in CEuvres Complètes, op. cit., p. 329.

${ }^{21}$ POLONSKY Rachel, "Poe's aesthetic theory », in HAYES, Kevin J. (ed.), The Cambridge Companion to Edgar Allan Poe, Cambridge University Press, 2002, p. 44-45.

22 "España es la que está loca, no yo », entrevista en El País con Jesús Ruíz Mantilla y Miguel Mora el 9 de agosto de 2005, http://elpais.com/diario/2005/08/09/ultima/1123538401 850215.html
} 
cuervo" hace Poe en la "Filosofía de la composición", ilustra perfectamente las palabras anteriores. El poema no es producto de una inspiración ingenua, nos dice Poe. Por el contrario, la creación artística vuelve a tomar la imagen del artificio preparado minuciosamente para el punto final. Sólo mediante el dénouement, el argumento de una obra puede presentarse como consecuente, cada palabra adquiere una causa, y la intención se vigoriza. La lectura debe producir en el lector un efecto, esto es, no cubrir meramente el espacio textual, el momento en el que se lee, sino además invadir el silencio, es decir, el momento en el que la lectura ha acabado, pero en el cual el lector sigue todavía inmerso. De ahí la importancia capital de ese efecto a la hora de constituir un texto:

I prefer commencing with the consideration of an effect. Keeping originality always in view for he is false to himself who ventures to dispense with so obvious and so easily attainable a source of interest - I say to myself, in the first place, "Of the innumerable effects, or impressions, of which the heart, the intellect, or (more generally) the soul is susceptible, what one shall I, on the present occasion, select?" Having chosen a novel, first, and secondly a vivid effect, I consider whether it can best be wrought by incident or tone - whether by ordinary incidents and peculiar tone, or the converse, or by peculiarity both of incident and tone - afterward looking about me (or rather within) for such combinations of event, or tone, as shall best aid me in the construction of the effect. ${ }^{23}$

Más aún, en la composición poética no hay ningún detalle que deba quedar a merced del azar o la intuición. Poe construye así una obra que se desarrolla con la precisión y el rigor lógico de un problema de matemáticas. De nuevo nos vemos obligados a repetir que, a pesar del rigor que se exige al poeta, nada tiene que ver su petición con las ciencias positivas sino que, muy por el contrario, no estamos hablando de otra cosa que de la búsqueda constante y trágica de la belleza, una belleza cuya más alta manifestación es la de la tristeza y la melancolía. Así, el autor va trazando el poema mediante una precisión sistemática del espíritu que se contraponga a la sistematización empírica. Y dentro de la tristeza, de todos los temas melancólicos, el más universal no puede ser otro que la muerte:

Now, never losing sight of the object supremeness, or perfection, at all points, I asked myself "Of all melancholy topics, what, according to the universal understanding of mankind, is the most melancholy? » Death - was the obvious reply. «And when,» I said, " is this most melancholy of topics most poetical? » From what I have already explained at some length, the answer, here also, is obvious - "When it most closely allies itself to Beanty: the death, then, of a beautiful woman is, unquestionably, the most poetical topic in the world - and equally is it beyond doubt that the lips best suited for such topic are those of a bereaved lover.» ${ }^{24}$

Detengámonos ahora unos instantes en la comparación de dos poemas que, a nuestro parecer, guardan una estrecha relación. Se trata de "La ciudad bajo el mar" y "20.000 leguas de viaje submarino". En el poema del madrileño se puede encontrar un primer indicio, una primera traza, de la poética del norteamericano ${ }^{25}$. En el poema de Poe,

\footnotetext{
${ }^{23}$ POE, Edgar Allan, "The Philosophy of Composition », in The Complete Works of Edgar Allan Poe (vol. XIV: Essays Miscellanies), op. cit., p. 194.

${ }^{24}$ Ibid., p. 201.

${ }_{25}$ Un primer indicio puesto que pertenece a su primer libro - que no plaquette - publicado, Así se fundó Carnaby Street, de 1970.
} 
encontramos todos los preceptos de la "Filosofía de la composición", referidos a la invención del poema, a la belleza y a la belleza melancólica, a la belleza de ultratumba, que hemos visto anteriormente. El texto, en efecto, describe con belleza la arquitectura exótica de una ciudad bajo el mar; ciudad dotada de una extraña hermosura puesto que es una belleza inútil, una belleza que el poeta puede atisbar pero que en realidad está escondida para el placer de los muertos:

There open fanes and gaping graves

Yawn level with the luminous waves

But not the riches there that lie

In each idol's diamond eye-

Not the gaily-jewelled dead

Tempt the waters from their bed;

For no ripples curl, alas!

Along this wilderness of glass. ${ }^{26}$

El poema de Panero, por su parte, parece continuar el tono del de Poe, pues también aquí el poeta nos habla desde la quietud de las profundidades. Sólo que en este caso, la referencia a la aguja, nos lleva a la idea de que el poeta asocia la tumba submarina con un estado narcótico ${ }^{27}$ :

Como un hilo o aguja que casi no se siente

como un débil cristal herido por el fuego

como un lago en que ahora es dulce sumergirse

oh esta paz que de pronto cruza mis dientes

este abrazo de las profundidades

luz lejana que me llega a través de la inmensa lonja de la catedral desierta. ${ }^{28}$

Ambos poemas están unidos por la imagen de una arquitectura sumergida. La inmensa lonja de la catedral se hermana con las cúpulas bizantinas de la ciudad de Poe, y ambas son percibidas en el momento epifánico en que una débil luz ilumina la belleza muerta o la belleza de la muerte:

No rays from the holy heaven come down

On the long night-time of that town;

But light from out the lurid sea

Streams up the turrets silently-

Gleams up the pinnacles far and free-

Up domes - up spires - up kingly halls-

Up fanes - up Babylon-like walls-

\footnotetext{
26 POE, Edgar Allan, The Complete Works of Edgar Allan Poe (vol. VII: Poems), op. cit., p. 50.

27 Tal idea se puede encontrar en las páginas que Túa Blesa dedica a este poema en su referencial Leopoldo María Panero. El último poeta, Madrid, Valdemar, 1995.

28 PANERO, Leopoldo María, "Veinte mil leguas de viaje submarino », in Poesía Completa (1970-2000), Madrid, Visor, p. 68-69.
} 
Up shadowy long-forgotten bowers

Of sculpture ivy and stone flowers-

Up many and many a marvellous shrine

Whose wreathed friezes intertwine

The viol, the violet, and the vine. ${ }^{29}$

Ahora bien, en el poema de Panero, la belleza sumergida no se ve, sino que la voz poética está en ella. Poe, en su poema, es el espía en el palacio bajo el mar, el palacio de los muertos. Panero toma ahora la máscara de uno de esos muertos. Y toma la máscara del muerto porque en este poema, como en tantos, Panero plantea la muerte no tanto como fin, sino como cambio, liberación o regeneración:

\author{
dejadme entonces besar este astro apagado \\ traspasar el espejo y llegar así adonde ni siquiera el suspiro es posible \\ donde sólo unos labios inmóviles \\ ya no dicen o sueñan \\ y recorrer así este inmenso Museo de Cera \\ deteniéndome por ejemplo en las plumas recién nacidas \\ o en el instante en que la luz deslumbra a la crisálida \\ y algo más tarde la luna y los susurros \\ y examinar después los labios que fulgen \\ cuando dos cuerpos se unen formando una estrella \\ y cerrar por fin los ojos cuando la mariposa \\ próxima a caer sobre la tierra sorda \\ quiere en vano volver sus alas hacia lo verde que ahora la desconoce..$^{30}$
}

De este modo, como estamos viendo, la belleza que surge a partir de los preceptos de Poe - y, por tanto, la que determina en una gran parte la de Panero -, a la vez que reprende al romanticismo por sus excesos, está inevitablemente emparentada con éste puesto que busca refugio ante el utilitarismo burgués, los malos tiempos para la lírica. Y este refugio se busca en lo que escapa a la disección positivista: la muerte, lo irracional. Como bien indica Julio Cortázar, Poe introduce el veneno de lo irracional dentro del aparato lógico, científico:

[...] creyéndolas fruto de la imaginación y el razonamiento, las modalidades que en él vienen de lo irracional, de lo inconsciente: la melancolía, la nocturnidad, la necrofilia, el angelismo y la pasión desatada, es decir, la pasión a salvo de cumplimiento, la pasión-recuerdo del que llora invariablemente a alguna muerta, a alguien que no puede ya amenazarlo deliciosamente con su presencia temporal. ${ }^{31}$

\footnotetext{
${ }^{29}$ POE, Edgar Allan, The Complete Works of Edgar Allan Poe, op. cit., p. 49.

30 PANERO, Leopoldo María, «Veinte mil leguas de viaje submarino » en Poesía Completa (1970-2000), op. cit., p. 69.

31 CORTÁZAR, Julio, «Introducción», en Edgar Allan Poe, Cuentos (vol. 1), Madrid, Alianza, 1999, p. 25.
} 
Pero esta búsqueda de lo irracional nos lleva a una búsqueda de la anormalidad, de lo que es, volveremos enseguida a esta noción, lo otro, lo monstruoso. « De la totalidad de elementos que integran su obra, sea poesía, sean cuentos, la noción de anormalidad se destaca con violencia $»^{32}$. En efecto, la noción de violencia, firmándose un nuevo pacto entre la poesía y el mal, en Poe está implícita en la noción de anormalidad:

Lo anormal del carácter de Poe se incorpora adventiciamente a su obra, aunque llegue a constituir el centro mismo de tantos relatos y poemas. Hay que entenderse en materia de centros, y el hecho de que un hombre le arranque un ojo a un gato, que es el eje de un cuento de Poe, no significa que el sadismo allí manifiesto baste para producir el cuento. La mayoría de los sadismos sólo los conocemos cuando un cronista policial nos informa de lo ocurrido. Dando vuelta a una famosa frase de Gide, no bastan los malos sentimientos para hacer buena literatura..$^{33}$

Se hace necesario aquí volver a recordar el abismo del que nos hablaba Baudelaire. Aquel que busca lo irracional está caminando por una senda salvaje y, donde no llega la razón, reina el horror. En El pacto con la serpiente, Mario Praz atribuye a Poe el descubrimiento de este reino para la poesía moderna, "La provincia que Poe ha descubierto, en verdad, no es tanto la de lo maravilloso y lo terrorífico exterior como el haber hecho de ellos un lenguaje transparente de su subterránea angustia ${ }^{34}$. El elemento que introduce Poe, la renovación que hace del género de terror, es que traslada el foco al aspecto más psicológico de éste:

Poe's greatest literary achievement was his renovation of the terror tale from what had been its principal intent, to entertain by means of "curdling the blood," to use a widely current phrase of the times, into what have been recognized as some of the most sophisticated creations in psychological fiction in the English language. He realized at the outset of his career that Gothicism was eminently compatible with psychological plausibility in literature, and he worked out such designs in combination repeatedly throughout his literary career. ${ }^{35}$

La voz de lo monstruoso en Poe consiste en que el horror, como hemos visto, toma la apariencia de la realidad, mediante un discurso que se fundamenta como lógico. Y es en este sentido en el que el terror le interesa a Leopoldo María Panero. Como dice en el prólogo a su estudio Visión de la Literatura de Terror Anglo-Americana:

El narrador se sitúa en el primer campo semántico, como negador privilegiado de la realidad de lo sobrenatural, que se presenta en este ámbito desacralizado más bien como algo que habría que llamar antinatural, contranatural: él es un incrédulo, un escéptico que no cree en los fantasmas hasta el final. Porque donde se sitúa el Terror es precisamente, como Poe intuyó tan certeramente en su ensayo sobre Hawthorne, en ese final del cuento. Y allí lo que sucede es la juntura de ambos campos, es decir, la realización del Terror, de lo irreal, pero sólo insinuada o manifestada como un corte en la narración (el protagonista se encuentra

\footnotetext{
32 Ibid., p. 17.

33 Ibid., p. 23.

34 PRAZ, Mario, El pacto con la serpiente, México, Fondo de Cultura Económica, 1988, p. 53.

${ }^{35}$ FISHER, Benjamin Franklin, «Poe and the Gothic tradition », in HAYES, Kevin J. (ed.), op. cit., p. 79.
} 
muerto en forma misteriosa), no prolongada, lo que sería la normalización de lo extraño y la muerte del Terror $[\ldots]{ }^{36}$

Poe da voz al terror, pero casi sería mejor decir que el terror es el protagonista de los relatos de Poe. Y también de los de Panero. En las siguientes líneas veremos todavía varios ejemplos del nuevo tratamiento del terror que inicia Poe, y que Panero recoge en su literatura. En "La caída de la Casa Usher », todos los elementos apuntan al terror y así, ya desde las primeras líneas, el narrador la describe en tonos lúgubres, y sin embargo, a pesar de todos los elementos, el terror o - para ser más precisos en estos primeros momentos de la historia - el desasosiego viene de una fuente que no se puede determinar, esto es, es un elemento que se deja entrever apenas, pero que no podemos definir claramente, justo antes, o recién pasada, la frontera de lo racional:

I looked upon the scene before me - upon the mere house, and the simple landscape features of the domain - upon the bleak walls - upon the vacant eye-like windows - upon a few rank sedges - and upon a few white trunks of decayed trees - with an utter depression of soul which I can compare to no earthly sensation more properly than to the after-dream of the reveller upon opium - the bitter lapse into everyday life - the hideous dropping off of the veil. There was an iciness, a sinking, a sickening of the heart - an unredeemed dreariness of thought which no goading of the imagination could torture into aught of the sublime. What was it - I paused to think - what was it that so unnerved me in the contemplation of the House of Usher? It was a mystery all insoluble; nor could I grapple with the shadowy fancies that crowded upon me as I pondered. I was forced to fall back upon the unsatisfactory conclusion, that while, beyond doubt, there are combinations of very simple natural objects which have the power of thus affecting us, still the analysis of this power lies among considerations beyond our depth. ${ }^{37}$

Todos los demás elementos ayudarán de la misma forma indefinible, intangible, al lenguaje: la casa, antaño casa de renombre, es ahora un lugar de decadencia, donde una velada historia de incesto se pudre entre sus dos fantasmales protagonistas, Roderick y Madeline Usher. También Panero, en el primero de sus libros de relatos, El lugar del hijo, nos presenta un relato teñido desde sus primeras líneas por un horror indefinido, cuya propia indefinición se convierte en aliada del horror:

[...] puede decirse que fue el miedo el único sentimiento que dio algo de vida a mi alma, y el único que siempre me llegaron a inspirar los seres humanos; $[\ldots]$

Mi propósito, debo reseñarlo, no sólo era conocerla, sino también indagar las verdaderas causas de aquella enfermedad y de aquella muerte oscura, porque presentía que había en todo ello algo extraño que una extraña y desconocida enfermedad de los trópicos; aunque nada de esto le dije a la que esperaba fuera en verdad mi segunda madre, o, dado que no había conocido a aquella otra a la que había dado muerte involuntariamente, acaso mi primera y única madre. ${ }^{38}$

Palabras que encuentran su eco en estas de Roderick Usher:

\footnotetext{
36 PANERO, Leopoldo María, Visión de la literatura de Terror Anglo-Americana, Madrid, Felmar, 1977, p. 19. ${ }^{37}$ POE, Edgar Allan, The Complete Works of Edgar Allan Poe (vol. III: Tales - Volume II), op. cit., p. 273-274.

38 PANERO, Leopoldo María, « Mi madre », en El lugar del hijo, Barcelona, Tusquets, 1976, p. 21 y 24.
} 
I dread the events of the future, not in themselves, but in their results. I shudder at the thought of any, even the most trivial, incident, which may operate upon this intolerable agitation of soul. I have, indeed, no abhorrence of danger, except in its absolute effect - in terror. In this unnerved - in this pitiable condition - I feel that the period will sooner or later arrive when I must abandon life and reason together, in some struggle with the grim phantasm, FEAR. ${ }^{39}$

Pero este miedo, como bien apuntaba Panero, sólo puede presentarse como una huida hacia delante, donde el horror que se paraliza deja de ser anormal y, por tanto, deja de provocar temor. De este modo, los relatos de Poe, pero también los de Panero, están marcados por un cruel crescendo, donde el terror sólo lo es un instante para dejar lugar a un horror aún más intenso. $\mathrm{Al}$ decir de Mario Praz:

En vez de una melodramática puesta en escena, con puertas que se abren y repentinas presencias de fantasmas (una puesta en escena explotada también en La máscara de la muerte roja) nos encontramos con la progresiva intensificación de una obsesión. Aquí la técnica es la del crescendo rossiniano del «aria de la calumnia» del Barbero de Sevilla: de un pianissimo a un fortissimo. 40

En efecto, si las primeras líneas del relato de Poe eran inquietantes, al final del relato, el dénouement, es sobrecogedor:

As if in the superhuman energy of his utterance there had been found the potency of a spell - the huge antique pannels to which the speaker pointed, threw slowly back, upon the instant, their ponderous and ebony jaws. It was the work of the rushing gust - but then without those doors there did stand the lofty and enshrouded figure of the lady Madeline of Usher. There was blood upon her white robes, and the evidence of some bitter struggle upon every portion of her emaciated rame. For a moment she remained trembling and reeling to and fro upon the threshold - then, with a low moaning cry, fell heavily inward upon the person of her brother, and in her violent and now final death-agonies, bore him to the floor a corpse, and a victim to the terrors he had anticipated. ${ }^{41}$

En «El presentimiento de la locura », título que Panero podría haber tomado de la obra homónima de Cioran, explota ese crescendo como técnica narrativa. Ya desde las primeras páginas, el autor / narrador nos da una referencia esencial para interpretar el relato: « $[\ldots]$ y mis tentativas infructuosas por hacer que éste [su nombre] tuviera algún sentido, dos libros de poemas enredados y amargos, escritos al dictado de la Philosophy of Composition de Poe, $[\ldots] »{ }^{42}$. En el relato, el escritor, significativamente llamado Arístides Briant ${ }^{43}$ narra su caída en el infierno del alcohol y de la locura; para evitarlo, adoptará un niño tullido, con una prótesis en una pierna que, si bien no despierta directamente una sensación de repugnancia en el padre adoptivo, sí se asocia en el discurso. De nuevo nos

\footnotetext{
39 POE, Edgar Allan, The Complete Works of Edgar Allan Poe, op. cit., p. 280.

${ }^{40}$ PRAZ, Mario, El pacto con la serpiente, op. cit., p. 70.

${ }^{41}$ POE, Edgar Allan, The Complete Works of Edgar Allan Poe, op. cit., p. 296.

${ }^{42}$ PANERO, Leopoldo María, El lugar del hijo, op. cit., p. 47.

43 Aristide Briand (con d) fue premio Nobel de la Paz y ministro del gobierno francés.
} 
encontramos, como en "La caída de la casa Usher » con una sensación que es indefinible por el lenguaje, con un terror - mejor sería decir aquí: con una fobia - que no podemos explicar, que surge de lo más profundo de nuestra psicología y, precisamente por ello, nos resulta infinitamente más insoportable:

[...] El niño cojeaba visiblemente, aunque no llegué a saber la causa hasta el final, ya que, al parecer, tanto los empleados del hospicio horrible como luego mi mujer, que habría de ser más tarde quien conociera el secreto de su desnudo, se esforzaron porque yo nada supiera.

Pero, aparte de su cojera, que a juicio de Cristina lo hacía más atractivo, fue algo indefinible lo que me hizo odiarlo: aunque no llegué a ser por completo consciente de que realmente lo aborrecía hasta mucho después, cuando ya era demasiado tarde. ${ }^{44}$

En «El corazón delator » de Poe encontramos un planteamiento narrativo que coincide en varios aspectos: el nacimiento de un odio indefinible, consustancial, como veremos, al propio Poe; el vínculo de convivencia indisoluble pero innatural (en el relato de Panero es un hijo adoptado; en el de Poe es un empleado que vive en casa de su patrón); la imposibilidad de eludir ese odio y, por tanto, la inevitabilidad de su realización en crimen; y, más específicamente, la presencia de un rasgo físico anormal:

It is impossible to say how first the idea entered my brain; but once conceived, it haunted me day and night. Object there was none. Passion there was none. I loved the old man. He had never wronged me. He had never given me insult. For his gold I had no desire. I think it was his eye! yes, it was this! He had the eye of a vulture - a pale blue eye, with a film over it. Whenever it fell upon me, my blood ran cold; and so by degrees - very gradually - I made up my mind to take the life of the old man, and thus rid myself of the eye forever. ${ }^{45}$

Un odio que desborda a su víctima por su indefinibilidad, convirtiéndolo en criminal. Un odio obsesivo imposible de erradicar del alma una vez se introduce, un odio que busca en vano razones, pero que ninguna causa puede tener sino el propio odio. Como dice Panero, "porque aquella maldad era sutil, no era terrena » ${ }^{46}$; o Poe, en " El demonio de la perversidad »: «In the consideration of the faculties and impulses [...] the phrenologists have failed to make room for a propensity which, although obviously existing as a radical, primitive, irreducible sentiment, has been equally overlooked by all the moralists who have preceded them ${ }^{47}$. Pero ese odio, ese sentimiento malsano e irreprimible, ese sentimiento que no se puede definir, en realidad no es sino el síntoma de algo más profundo: la locura que arrastra a los personajes de nuestros dos autores, quizá porque son la sospecha de las mentes que crearon estos personajes, como dice Sabine Klein de Poe:

Übers Phantastische bei Poe ist allenmal schon viel gestritten worden. Immer wieder hat man es als eine Technik der systematischen Verfremdung von Wirklichkeit beschrieben vermöge des Opiumsrauchs, der Halluzination, des Wahns, wobei freilich [...] die Meinungen darüber auseinandergingen, ob der offenkundinge Wahnsinn der Texte nun ein

\footnotetext{
44 PANERO, Leopoldo María, El lugar del hijo, op. cit., p. 49.

${ }^{45}$ POE, Edgar Allan, The Complete Works of Edgar Allan Poe (vol. V: Tales - Volume IV), op. cit., p. 88.

46 PANERO, Leopoldo María, El lugar del hijo, op. cit., p. 56.

${ }^{47}$ POE, Edgar Allan, The Complete Works of Edgar Allan Poe (vol. VI: Tales - Volume V), op. cit., p. 145.
} 
Effekt des Künstlerischen sei oder Spiegelung des desolaten Geisteszustandes ihres Authors. ${ }^{48}$

Pero esa locura, que puede llegar a esbozarse solamente como una sospecha, como una posibilidad en Poe es tristemente una certeza por todos conocida en el caso de Leopoldo María Panero:

No puede quedar sin ser aludida la más que singular biografía del escritor, esa "locura" que lo convirtió hace ya años en figura legendaria, en psiquiatrizado y en habitante de clínicas y manicomios [...] E importa dejarlo dicho no ya por la morbosidad del asunto, sino porque esa "locura" amenaza o arrastra [...] a muchos de los personajes de sus narraciones. ${ }^{49}$

Interesa recordar sin embargo, como hemos hecho ya en la introducción, que esta correspondencia entre la vida y la obra va mucho más allá de la simple plasmación de lo biográfico sino que, por el contrario, en Panero esto significa la asunción del principio nietzscheano que nos invita a vivir la vida, a construirla, como si fuera una obra de arte. Es cierto que la escritura paneriana está plagada de datos, en mayor o menos medida distorsionados, procedentes de su biografía, pero no lo es menos, y esto es mucho más importante, que ese es un flujo que funciona en ambos sentidos y que su escritura determina igualmente la vida, haciendo de la fusión de ambas un todo inseparable, que es lo que por algunos ha venido a ser llamada « locura». Volviendo al análisis que nos ocupa, por otra parte, hemos visto ya las huellas de Poe que se encuentran en la escritura paneriana; sin embargo, nuestro análisis no se para en la búsqueda de esas fuentes que ya se han mostrado sino que, para terminar nos centraremos en otro punto que ya hemos anotado en las primeras líneas de este texto. Y es que, si bien es cierto que la obra de Leopoldo María Panero es un cuerpo construido a base de otros cuerpos, un Frankenstein impresionante donde otros textos se funden en una unidad superior, no es menos cierto que esas huellas, esas partes que constituyen los textos panerianos son sometidas a la insoportable presión de una reescritura que se enseñorea de los textos originales. Y esto porque la escritura de Panero es una escritura vitalista, que busca dominar. Por tanto, para terminar, presentaremos dos ejemplos que son bien significativos de cómo el poeta madrileño se apropia de la obra de Edgar Allan Poe, reescribiéndola y pervirtiéndola.

Si hasta aquí habíamos visto que ambas obras se encuentran marcadas por el odio injustificado, el odio que nos domina en un éxtasis incontenible. No menos inquietante, no menos trascendental para ambas escrituras es otro tipo de odio aún más terrorífico: ese odio invencible hace que nos veamos a nosotros mismos como otro y, lo que es aún más terrible, como un otro que se materializa, convirtiéndose en antagonista. Estamos hablando de "William Wilson":

En el romanticismo alemán encontró Poe asimismo la figura del sosias, del Doppelgänger, con la cual Hoffmann había identificado aspectos disociados de la personalidad, siguiendo las huellas de un volumen de psicología de G. H. Schubert publicado en 1814, Die Symbolik des Traumes. Por cierto que los sosias alemanes tienen algo de terrorífico [...] Pero en William Wilson Poe logra dar un sesgo terrorífico y melodramático al ya gastado motivo romántico

\footnotetext{
${ }^{48}$ KLEIN, Sabine, Zur Ästhetike des Häßlichen, Stuttgart, Verlag J. B. Metzler, 2002, p. 115.

49 BLESA, Túa "Relatos de muertos ", in Leopoldo María Panero, Cuentos completos, Madrid, Páginas de Espuma, 2007, p. 9-10.
} 
del sosias, que en él personifica la conciencia, el lado bueno de William Wilson, que lo persigue con sus admoniciones. ${ }^{50}$

En efecto, en este relato, Poe habla de un William Wilson, que conoce en la universidad a otro William Wilson idéntico, por lo demás, físicamente al primero. Los dos William Wilson se hacen amigos, pero pronto se produce una escisión entre ellos; uno, el narrador, se hunde en las ciénagas de la depravación, mientras el otro se mantiene en el camino de la honradez. A partir de este momento, el segundo Wilson irá apareciendo esporádica y fantasmalmente a lo largo del relato con el propósito de desbaratar las tropelías que el narrador urde. El cuento tiene un desenlace espectacular, digno de la teoría poética del propio Poe, en el cual, en la Venecia de los Carnavales, el Wilson malo da muerte al Wilson bueno; es entonces cuando se desencadena el horror en toda su potencia:

Thus it appeared, I say, but was not. It was my antagonist - it was Wilson, who then stood before me in the agonies of his dissolution. His mask and cloak lay, where he had thrown them, upon the floor. Not a thread in all his raiment - not a line in all the marked and singular lineaments of his face which was not, even in the most absolute identity, mine own!

It was Wilson; but he spoke no longer in a whisper, and I could have fancied that I myself was speaking while he said:

"You have conquered, and I yield. Yet, henceforward art thou also dead - dead to the World, to Heaven and to Hope! In me didst thou exist - and, in my death, see by this image, which is thine own, how utterly thou hast murdered thyself $» .51$

En el poema de Panero “Ann Donne: Undone”, leemos:

Tantas veces he creído escuchar

William Wilson, tus pasos, detrás de mí, a lo largo de los interminables Corredores

Desnudos como el Invierno

Como el invierno propicio a fantasmas y Ecos,

Tantas veces, tantas veces tus pasos he creído escuchar

William Wilson, detrás de mí

En los interminables Corredores como la sombra del Castillo a que éstos conducen. ${ }^{52}$

Ahora bien, de la misma manera que Poe transformaba la figura del doble, recogida de los alemanes, Panero, a su vez, transforma el sentido del personaje de Poe. Como él mismo dice en una entrevista:

En lugar de tratar de buscar en la realidad o de describir el infinito, de lo que se trata es de inventarlo y construirlo. En "Ann Donne: Undone" es donde empieza todo ese trabajo metódico de destrucción del mundo. [...] En mi poema, William Wilson también simboliza lo mismo: es el doble que tratas de buscar pero que no existe. Es la mujer y la destrucción del amor como verdades absolutas. Como dice al final del poema: William Wilson no existe, o en

\footnotetext{
${ }^{50}$ PRAZ, Mario, Elpacto con la serpiente, op. cit., p. 69.

51 POE, Edgar Allan, The Complete Works of Edgar Allan Poe (vol. III: Tales - Volume II), op. cit., p. 325.

52 PANERO, Leopoldo María, « Ann Donne: Undone », in Poesía Completa (1970-2000), op. cit., p. 71.
} 
todo caso nos conduce a las cenizas. Y la comparación entre la mujer y la poesía es el salón de los espejos a favor de esta última. Niega todo lo demás..$^{53}$

Así, del mismo modo que William Wilson es en Poe la imposibilidad de discernir la moral (el mal muere al matar al bien), en Panero William Wilson es otra imposibilidad, la de la poesía, la sonrisa de la Esfinge:

No es verdad que ahora los escuche,

No es verdad y es verdad la sonrisa de la Esfinge

Porque la única verdad es aquello que no es verdad

Y la única esperanza en la tierra aquello que está

Fuera del Mundo y en el Mundo

Fuera del Mundo y de la Tierra.

No es verdad William Wilson,

WILLIAM WILSON NO EXISTE

O al menos no es Aquel que nos salvará de la Ceniza

Pues es él mismo quien nos conduce a la Ceniza:

Las cadenas del Demonio se deshacen con inocente crueldad en las manos de los Sedientos ${ }^{54}$

Un ejemplo más patente de la reescritura que Panero hace de la obra de Edgar Allan Poe es el que nos proporciona Ignacio Rodríguez de $\operatorname{Arce}^{55}$ al comparar las dos versiones del poema «Annabel Lee ». En efecto, en la reescritura paneriana se produce una serie de modificaciones que sirve para, traicionando el significado, desmontar la jerarquía del texto. El texto cita, sí, pero no se subyuga, no acepta la distinción entre texto primario o fuente y texto secundario, muy por el contrario, el texto secundario anuncia su irrefrenable libertad con la traición a la fidelidad. Se produce entonces un desplazamiento que es significativo, esto es, introduce un discurso que atenta contra el discurso hegemónico. Y esto es así, por ejemplo, con el travestimiento de la voz poética, que en Poe es claramente masculina ( I was a child and she was a child, / In this kingdom by the sea $)^{56}$, mientras que en el texto paneriano se produce una inversión de género, un travestimiento que introduce una variable de transgresión homosexual: Yo era una niña y ella casi un niño / nadando los dos bajo el mar ${ }^{57}$. Aún más, no sólo está este cambio sino que ambos niños nadan bajo el mar, como ahogados en la anteriormente vista «Ciudad bajo el mar ». Pero aún más diferencias encontraremos si comparamos todavía estos versos de Poe:

And this was the reason that, long ago,

In this kingdom by the sea,

\footnotetext{
${ }^{53}$ CAMPBELL, Federico, Infame turba, Barcelona, Lumen, 1971, p. 19-20.

54 PANERO, Leopoldo María, «Ann Donne: Undone », in Poesía Completa (1970-2000), op. cit., p. 73.

${ }_{55}$ RODRÍGUEZ DE ARCE, Ignacio, « Poética de la intertextualidad en Leopoldo María Panero », op.cit., p. 34-35.

${ }^{56}$ POE, Edgar Allan, The Complete Works of Edgar Allan Poe (vol. VII: Poems), op. cit., p. 116.

${ }^{57}$ PANERO, Leopoldo María, « Annabel Lee », in Poesía Completa (1970-2000), op. cit., p. 217. Hay que añadir, además, que no son en absoluto raros estos travestimientos de la voz poética en la obra de Leopoldo María Panero; muy por el contrario, la sexualidad es para nuestro autor un espacio abierto donde los límites no existen y, si existen, son solamente una excusa para ser vulnerados. La libertad sexual en la obra de Panero, además, no conoce límites y, así, no sólo travestimiento, sino incesto, violencia, necrofilia, pedofilia entre otras prohibiciones sociales recorren sus páginas.
} 
A wind blew out of a cloud, chilling

My beautiful Annabel Lee;

So that her highborn kinsmen came

And bore her away from me,

To shut her up in a sepulcher

In this kingdom by the sea. ${ }^{58}$

con el terrorífico palimpsesto que produce Panero:

Y fue ese el motivo quizás por el que un día

una lágrima cayó del cielo disolviendo

como un ácido el cuerpo que temblaba

de mi hermosa, de mi pálida ANNABEL LEE, y entonces

vinieron sus padres, gente de dinero

a hacerse cargo del alma, y dicen

que la enterraron bajo el mar.

$[\ldots]$

Pero hoy los huesos de una niña bailan

allí junto a una roca, cerca

de aquel reino moribundo que hay

debajo del mar, y cantan

aún esa canción demente, la

de los seres que

se enterraron juntos pronunciando

a solas el nombre de

ANNABEL LEE. ${ }^{9}$

Como dice Rodríguez de Arce, "Panero introduce versos que intensifican la dimensión unheimlich ${ }^{60} ; \mathrm{y}$, ciertamente el desplazamiento, que tenemos es indudablemente siniestro, Annabel Lee ya no ha sido llevada lánguidamente por un viento hacia la muerte sino que su cuerpo se ha deshecho, como la carne en el Valdemar de Poe, y además temblando. Sus padres, que pasan de ser gente de alta cuna a gente de dinero - el matiz es casi carnavalesco -, la entierran - una vez más - bajo el mar, pero lo monstruoso alcanza su punto álgido, como en las composiciones de Poe que hemos visto en las páginas anteriores, en el dénouement. el cadáver de Annabel Lee, sus huesos, bailan, como en un infernal aquelarre, cerca del reino que está - una vez más - bajo el mar, mientras toda su civilización perece. Y es que, la amplificación de lo monstruoso en la escritura paneriana es un crescendo que sólo conoce un límite: el silencio del texto que termina.

\section{Nevermore}

\footnotetext{
${ }^{58}$ POE, Edgar Allan, The Complete Works of Edgar Allan Poe (vol. VII: Poems), op. cit., p. 117.

59 PANERO, Leopoldo María, «Annabel Lee », in Poesía Completa (1970-2000), op. cit., p. 217.

${ }^{60}$ RODRÍGUEZ DE ARCE, Ignacio, « Poética de la intertextualidad en Leopoldo María Panero », op. cit., p. 34.
} 
La escritura de Leopoldo María Panero, en conclusión, se reescribe, se fundamenta y se constituye como una red textual que atrapa otros discursos. La selva paneriana se hace de infinitos discursos mutilados que decoran sus ramajes con sus voces extirpadas. Ahora bien, esos injertos, esos intertextos están en las antípodas de ser neutros homenajes. Muy por el contrario, Panero nos propone su obra como la Esfinge proponía a los infortunados habitantes de Tebas, como una serie de acertijos mortales donde el juego no consiste en localizar la cita, eso es sólo el comienzo, sino en descifrar, como una mantiké, los signos que esta cita nos propone:

[...] el propio poema debe preparar al lector a una interpretación intertextual a través de una serie evidente de señales, construyendo o elaborando una autónoma "disposición intertextual”. En el caso de la poesía de Leopoldo María Panero dicha "disposición”, lejos de aparecer marcada explícitamente, aunque también lo hace en los innumerables casos en los que el lector entra en el texto ajeno de la mano del poeta a través de los epígrafes que encabezan los poemas, o del uso de comillas o cursivas, es una implícita trabazón que recorre transversalmente todo el corpus poético del madrileño, que en cierta medida no es sino puro y continuado ejercicio de reelaboración de alguna página de otro. ${ }^{61}$

Debajo de todos esos signos, sin embargo, debajo de toda esa diferencia, hay una repetición que vertebra la obra, un programa revolucionario mediante el cual la literatura se convierte en un artefacto subversivo " el ejercicio intertextual que constituye la poética de Panero, como el mismo explicita en el "prefacio" de El último hombre (1983), siguen dos líneas de significación, dos técnicas, claramente definidas: i) la búsqueda de la inquietante extrañeza y ii) el extrañamiento ${ }^{62}$. Es mediante esta extrañeza, mediante este extrañamiento, mediante los cuales los tabús, que son las primeras fronteras, las más inflexiblemente cerradas, se cuestionan. $\mathrm{Y}$ es en este punto en el que la obra paneriana se nutre de la de Poe:

Bedingunglos ordnete Poe in seinen kunsttheoretischen Schriften den Stoff den Absichten des Künstlers unter. Seither gab es kein besonderes Material für die Herstelleung des Kunstschönen mehr, kein a priori Feines oder Grobes, Schönes oder Häßliches; hinsichtlich des Sujets des Ästhetischen sollte kein Tabu existieren. ${ }^{63}$

Ahora bien, lo monstruoso no admite parentescos e, igual que los libertinos sadianos pactaban con el presupuesto de que estos pactos se iban a traicionar en cuanto conviniera a cualquiera de sus miembros, lo monstruoso en Panero va más allá de la convención y no obedece a más ley que su propia violencia irredenta:

[...] en nombre de raras creencias, de la locura, del alcohol o las drogas, las narraciones de Panero son espacios recorridos por la violencia desencadenada. Los territorios fantásticos sirven, pues, a la comisión de actos ilegales, inmorales, como si la humanidad se hubiese retrotraído a un estado salvaje sin ley alguna. ${ }^{64}$

\footnotetext{
${ }^{61}$ RODRÍGUEZ DE ARCE, Ignacio, « Poética de la intertextualidad en Leopoldo María Panero », op. cit., p. 31-32.

62 PANERO, Leopoldo María, «Prefacio », El último hombre, in Poesía completa (1970-2000), op.cit., p. 287.

${ }^{63}$ KLEIN, Sabine, Zur Ästhetik des Häßlichen, op. cit., p. 113.

${ }^{64}$ BLESA, Túa, « Relatos de muertos », in PANERO, Leopoldo María, Cuentos completos, op. cit., p. 22.
} 
Y esta violencia, no nos cansaremos de repetirlo es la razón y la finalidad por las que Leopoldo María Panero combatió toda su vida, sus 65 años, no sólo con su obra sino también con su biografía, haciendo de cada instante de su existencia un segundo de lucha, de resistencia contra la moral establecida, contra el sistema. La poesía de Leopoldo María Panero, por tanto, es monstruosa no sólo en su contenido, en lo horrendo que destruye los parámetros burgueses de belleza; también es poesía monstruosa porque convierte a su portador a la vez en sacerdote y en mártir. Una búsqueda de lo absoluto, más allá del bien y del mal, que exige un sacrificio total. Y este sacrificio se hace entonces no sólo martirio sino trasgresión: "Si se dedica uno a la poesía tiene que negar absolutamente todo lo demás. No sólo teórica sino vitalmente. Hay que producir un adelgazamiento progresivo hasta llegar a ser únicamente lo que es el libro ${ }^{65}$.

${ }^{65}$ CAMPBELL, Federico, Infame turba, op. cit., p. 20. 